\title{
Improvement in Sleeper Casting Process - A Case Study from Ghana
}

\author{
${ }^{* 1}$ P. Guru Raju, ${ }^{2}$ Ramesh Mani Vishwakarma, ${ }^{3}$ A.K.Sharma \\ ${ }^{1,2}$ Afcons Infrastructure Limited, Mumbai, Maharashtra \\ ${ }^{3}$ Shri Ramdeobaba College of Engineering and Management, Nagpur \\ Email: gururaju.pokkunuri@afcons.com,ramesh.vishwakarma@afcons.com,sharmaak@rknec.edu
}

Received: 20th November 2019, Accepted: 10th February 2020, Published: 29th February 2020

\begin{abstract}
This project involves construction of Single Standard Gauge Railway line from Tema to Akosombo on EPC Basis in Ghana, West Africa. One of the major scopes of work is casting of railway sleepers. The quantity of sleeper to be cast for the construction of rail track is approx. 200,000 in numbers. Thus, production of the sleeper was on a critical path, to complete the project within the scheduled time. During the initial production period, it was observed that performance of the sleeper plant was not effective. The rejection rate was as high as $3.18 \%$ of the days production. This high rate of rejection will have an impact on the cost as well as completion time of project leading to performance of the organisation in the region. This paper describes how the project team was able to effectively identify and eliminate the possible reasons for rejection of railway sleepers using the root cause analysis. This has not only improved the quality of the product but also demonstrated the capability of the team to handle the big projects effectively. Collaborative efforts were carried out along with the supplier to eliminate possibility of recurrence.
\end{abstract}

Keywords

Root Cause Analysis, Sleeper Production, Ballasted, Railway Track.

\section{Introduction}

Afcons Infrastructure Limited has been awarded with the Project "Construction of Single Standard Gauge Railway line from Tema to Akosombo on EPC Basis" in Ghana, West Africa. The project scope includes construction of $98 \mathrm{Km}$ Railway track comprising of Ballasted Track with Pre-Stressed-Concrete (PSC) sleepers \& UIC 54 Rails over the sleepers. Keeping in view the asking rate for production of railway sleeper, Long Line method with Pre-Engineered-Building (PEB) was proposed to setup near the base camp. The plant was installed \& commissioned quickly with a capacity to produce 720 numbers of sleepers per day. During the Initial phase of production period the rejection rate was high. The rejection was mainly due to the breaking of sleeper experienced during de-stressing \& also due to honeycomb observed in the edges of sleeper for each production lot. This high rate of rejection will have an impact on the cost as well as completion time of project leading to performance of the organisation in the region. Therefore, it was necessary to analyse the rejection in a structured way to arrive at the main cause of defects leading to rejection and permanently eliminate the issue.

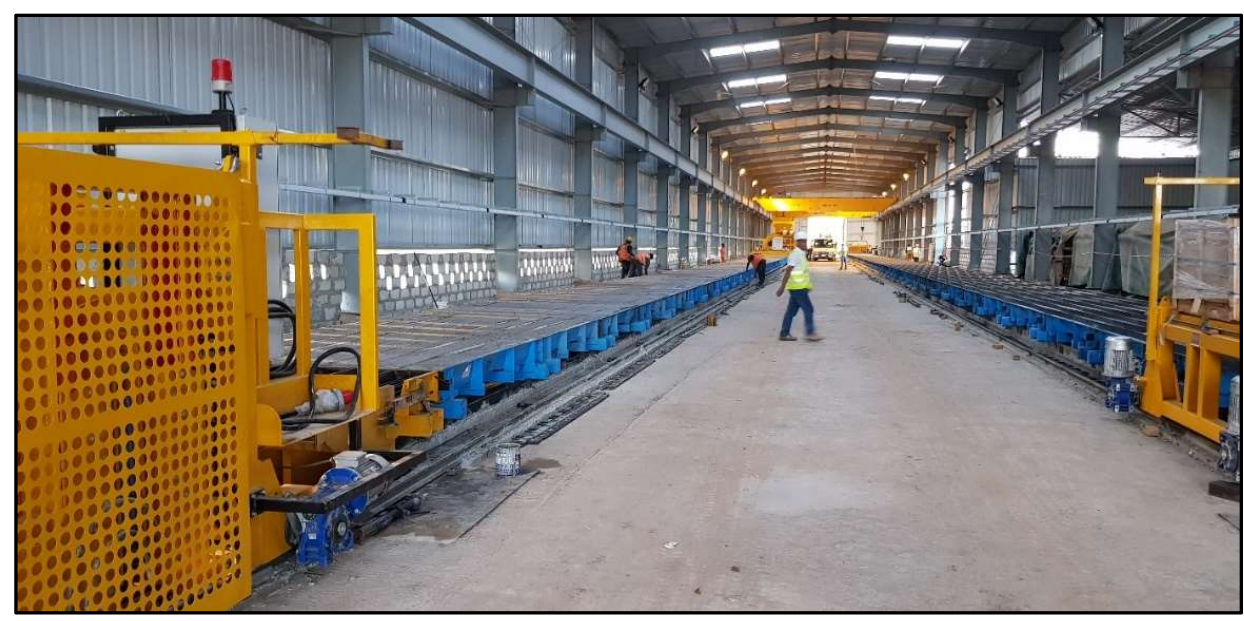

Figure 1: Inside View of Sleeper Production Plan

Root cause analysis is a structured method used to address a problem in order to get the main cause of the problem or defects [1]. RCA gives the confidence that the problem can be solved by taking a structured approach - making sure that the problem never happens again. To improve efficiency and profitability, we need to look beneath the surface to the root of a problem or issue. By observing the effect which is just the symptom of a problem and deducing what has caused it to occur, we can create a preventive solution that should put an 
end to the problem. Before getting into the RCA it is required to understand the process of production of sleeper. The methodology adopted in sleeper production is detailed below for understanding the process.

\section{Methodology of Sleeper Production}

The production of sleepers is done systematically by following the standard method of production to meet the specification. [2] The first step is preparation of moulds for casting by proper cleaning and greasing. The cast-in fastening components are placed in the mould as shown in Figure 2.

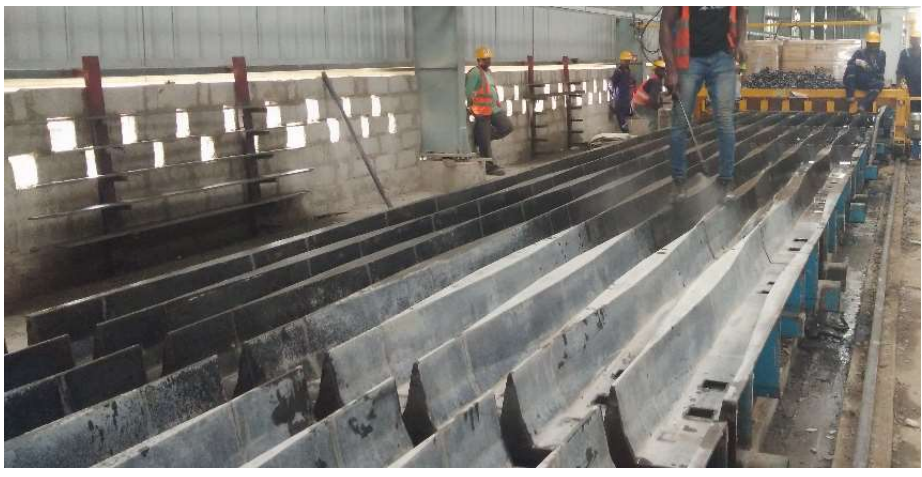

Figure 2: Cleaning and Greasing of Mould

Then $8 \times 8$ numbers of High-Tension-Strands (HTS) wires are placed in a predetermined position in each line. They are then pre-tensioned by a hydraulic jack to give a certain initial pre-stress force as shown in Figure.

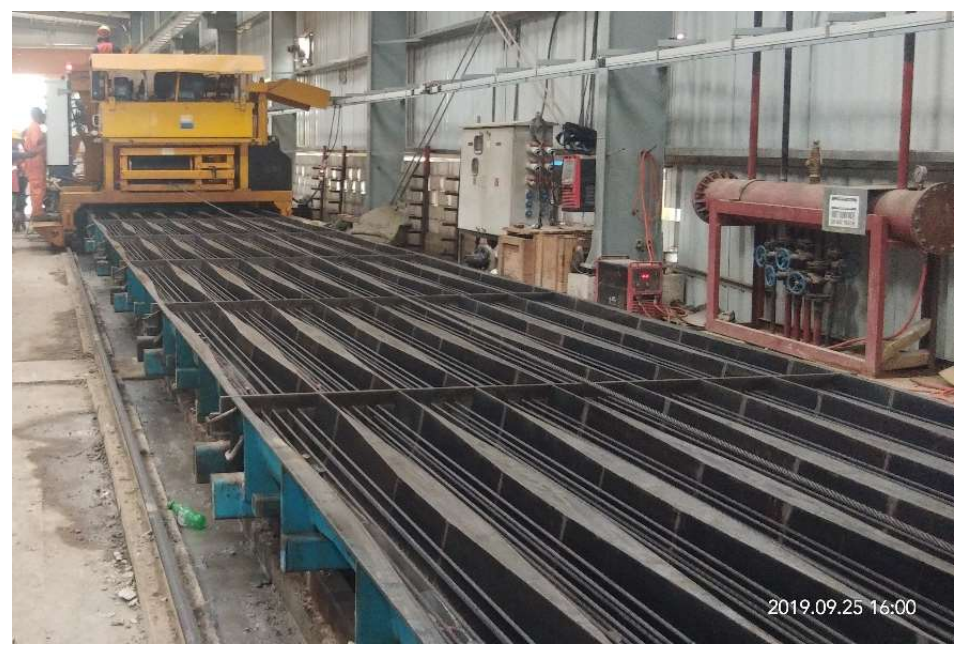

Figure 3: Placing of HTS Wires in Position for Stressing

Casting of sleepers using a mechanical casting machine [3] as shown in Error! Reference source not found. which is a continuous process till completion of concrete for the entire casting line. The casting process generally take 3 to 4 hours to complete one line. 


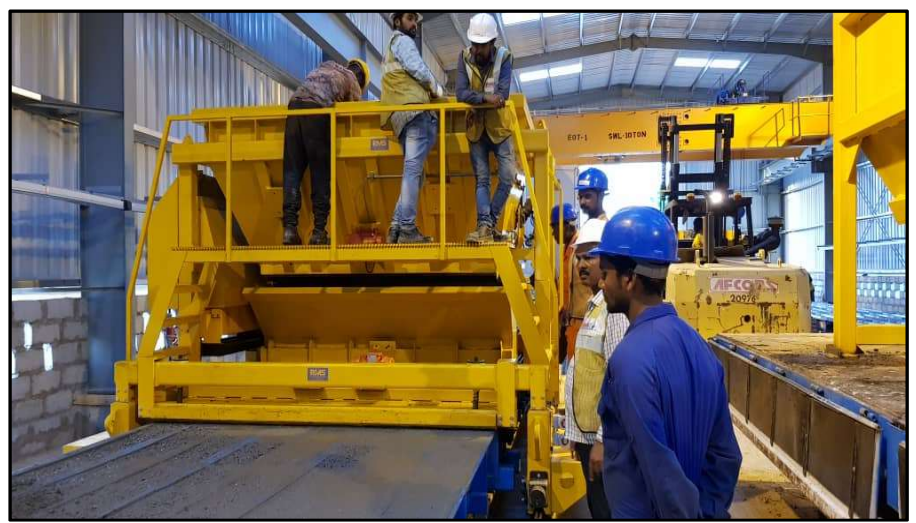

Figure 4: Concreting of Sleepers with Mechanical Casting Machine

The concreted line has been covered with Tarpaulin and waited till completion of initial setting time of two hours. Once the Initial Setting time is completed, Steam Curing process initiated as shown in Figure and continued for 10 to 12 hours until the required strength of concrete achieved. When the temperature starts to decrease and the compressive strength of $40 \mathrm{MPa}$ is achieved, the sleepers are safe to release of the pre-stressing force.

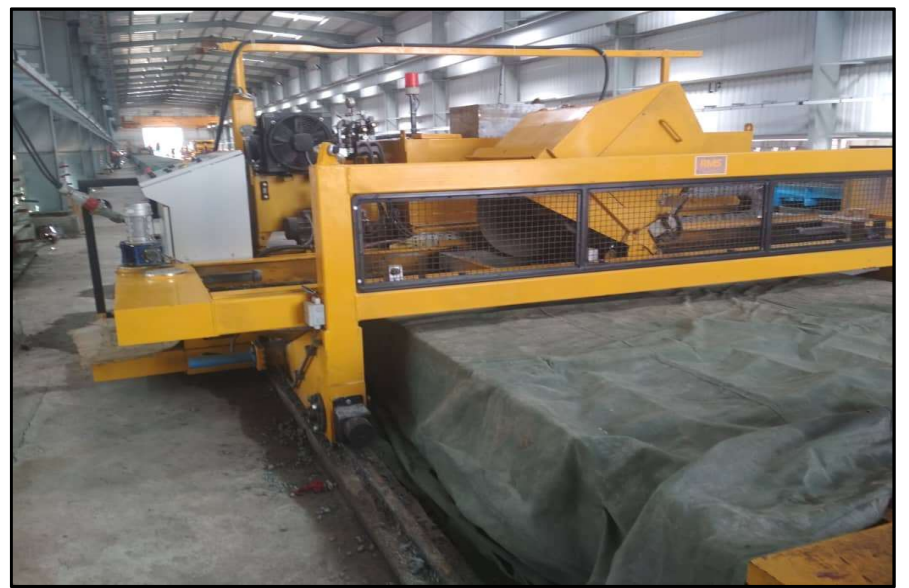

Figure 5: Steam Curing for Concrete Sleepers

Once the steam curing time is completed, the stress released for HT Strands by cutting as shown in Figure Sleepers are then de-moulded by demoulding and cutting machine which they are cut to exact length with a diamond saw.

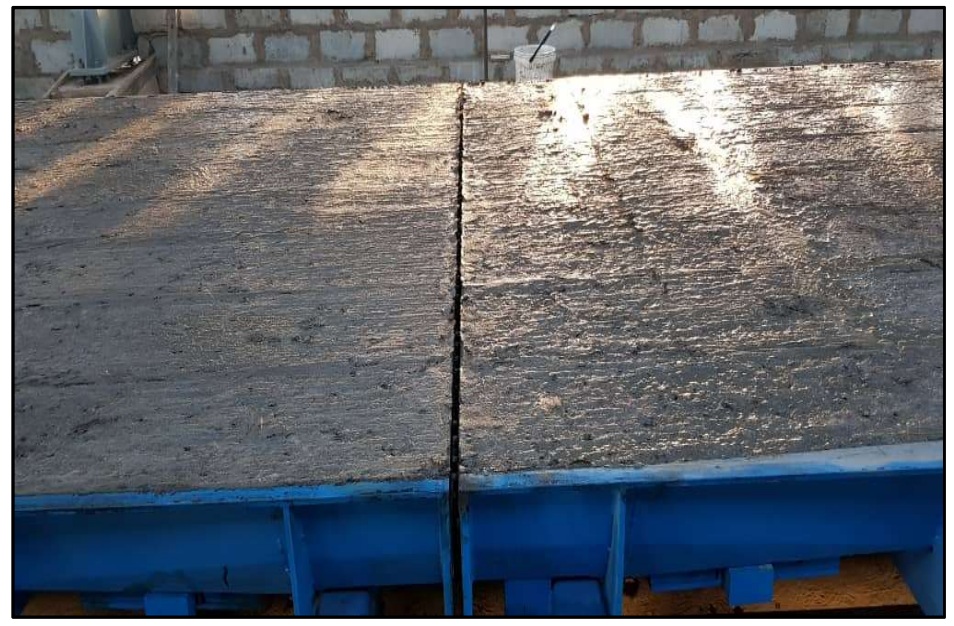

Figure 6: Cutting of HTS Wires to Destress the Sleepers 


\section{Reason for Rejection}

During de-stressing two issues observed in the final product one is breaking and second is honeycomb in sleepers as shown in Figure. The initial rejection of sleepers was approximately $3.18 \%$ as shown in Table 1 which indicates the need to eliminate the rejection from the process to improve the productivity.

\begin{tabular}{|l|c|c|c|}
\hline \multicolumn{3}{|c|}{ REJECTION OF SLEEPER IN THE MONTH OF APRIL'2019 } \\
\hline \multirow{2}{*}{ MONTH } & \multicolumn{2}{|c|}{ PRODUCTION } & \multirow{2}{*}{ TOTAL PRODUCTION } \\
\cline { 2 - 3 } & LINE ONE & LINE TWO & 3240 \\
\hline APRIL -19 & 1440 & 1800 & 103 \\
\hline Total Rejections & 62 & 41 & 3.18 \\
\hline$\%$ of Rejection & 4.31 & 2.28 & \\
\hline
\end{tabular}

Table 1: Initial Rejection of Sleeper



Figure 7: Breaking and Honeycomb in Sleeper

\section{Root Cause Analysis (Breaking of Sleeper)}

The cast sleepers were properly steam cured to achieve the required strength under controlled condition for Demoulding and removal of sleepers by cutting the HTS strand. In the process it was observed that the sleeper gets damaged by edge breaking.[4] Initially brainstorming session was conducted at site with key stakeholders to understand the difficulties in the production process of sleeper. Root cause analysis was initiated to identify the main cause of breaking of sleepers during destressing. The three possible causes were identified as the possible cause of breaking of sleepers during destressing as detailed below. Each possible cause was further investigated to check the potential cause of failure [5][6]

1. Cutting location of HTS wire may not be correct.

2. In-sufficient de-stressing stroke during releasing of jack.

3. Slippage of HTS wire during cutting.

\section{Cutting Location of HTS Wire}

Initially the strands were cut at the centre portion of the long line and later at both ends. Then trials were done by changing the sequence of cutting, it was observed that cutting location of the HTS strands has no role to play in the cracking of sleepers.

\section{In-sufficient de-stressing stroke during releasing of jack}

The stressing pattern and elongation of HTS wires between the moulds and at the ends (Live \& Dead) were checked. It was observed that the stroke of de-stressing jack is enough to release the stress of remaining HTS wire. Thus, it was concluded that the defects observed in the sleeper are not due to the stroke of releasing jack.

\section{HTS Wire is slipping from concrete during cutting}

The releasing stroke to be given by the stressing jacks was calculated as per the elongation of the standard unembedded wire of the bed \& then checked the Anchorage bond between the Concrete \& embedded HTS wires after de-stressing.[7] It was observed that there is slippage in the HTS wires which is embedded inside the concrete. As the extra-elongation of wire was not considered in the releasing stroke of the de-stressing jack additional stress developed in the strand. This additional stress in the HTS wire causing thrust on the face of the 
sleeper resulted in edge breaking. Thus, excess slippage of HTS wire needs to be controlled in order to safeguard the breaking of edges in the sleeper. Hence it was necessary to understand the main cause of slippage of HTS strand in the sleeper. Further it was concluded by conducting brain storming session that the possible reasons of slippage of HTS strand could be

A. Poor bond strength between concrete and HTS wire in position.

B. HTS wires placed were not meeting the required specification.

\section{A. Poor bond strength between concrete and HTS wire - Possible cause Proper compaction of concrete?}

The workability of the mix was modified, and in-house vibrators were developed to increase the compaction efforts in sleeper casting. This has improved the honeycomb issue, but the slippage was still more than the stipulated norms.

\section{Concrete Mix Design?}

For finding out the causes of slipping of HTS wires we have adapted the finer gradation of concrete mix design keeping in same envelope of gradation by increasing the percentage of Fine aggregates and with same grade of concrete still we observed the slippage of embedded HTS wires and performed further analysis.[8]

\section{B. $\quad$ HTS Wires are of required quality - Possible cause}

The physical and chemical properties of HTS wire were checked through MTC as well as Third Party laboratory test reports and established the acceptance of the material.

Based on visual inspections HTS wires were coated with grease to keep the material corrosion free during transportation. The application of grease was in excess, contributing the poor development of bond strength between the wire and the concrete. Trials were done using the cleaned wire to produce sleeper.

Initially, measures have taken to remove the excessive grease manually using Jute \& cotton cloths. It is observed that the slippage of embedded strands is not within the permissible limits. The traces of grease were evident in the strand as shown in Figure. As an improvement the cleaning of deposited grease in the HTS wires was tried by application of jet spray using normal water. It was observed that grease deposited inside the core is not being removed in this process. Therefore, during destressing the slippage of HTS wires again recorded beyond the specified limit.



Figure 8: Excess Grease Application on HTS Wire

Finally, improved process was tried by submerging the HTS strand coil in the lime solution and then application of jet spray for cleaning the strand. This process has improved the performance of the HTS wire in the sleepers significantly. It was observed that the slippage was within permissible limits during the process of destressing for sleepers. This resulted in improving the sleeper quality by eliminating defects like broken edges or crack development of sleeper during destressing. Finally, non-grease coated HTS wires were also tried in the sleeper production from alternate source instead of grease coated HTS wire. It was observed that no crack and slippages of HTS wire in the Sleeper is evident.

\section{Results and Discussion}

The improvement in the quality of sleepers produced during the subsequent months showed the effectiveness of the root cause analysis done by the project team. The rate of rejection was constantly reduced starting from the month of May'2019 till August'2019 from 3.16\% to $0.053 \%$ with overall rejection till date being $0.89 \%$ as 
shown in 9. The change in process of using the existing HTS wire and ordering the new with no coating on the strands helped the project to control the rejection of sleeper during production. The Root Cause Analysis for defects such as edge breaking in sleepers is captured using ' 5 whys' technique in a flow diagram as shown in 10. Corrective action implemented in the production of sleeper and reduced the reject rate to $0.053 \%$ by the end of August'2019.

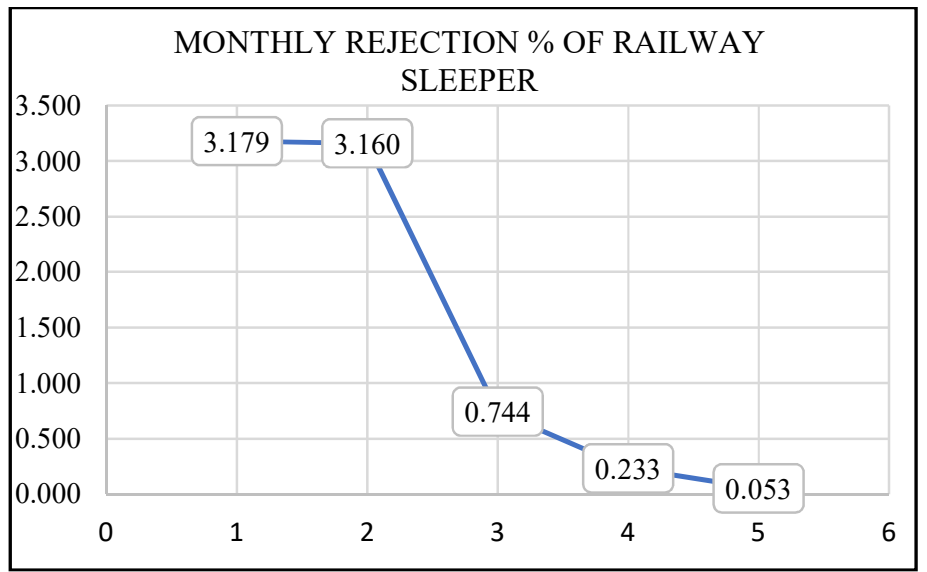

Figure 9: Monthly Rejection Rate for Sleepers Starting April’2019



Figure 10: Flow Chart for Root Cause Analysis for Breaking of Sleeper at Ghana Project

\section{Conclusion}

Root-cause analysis is done to identify the main or real cause of the defect. It helps in improvement of quality and productivity in the process. It has been a very challenging engineering problem particularly in a multistage manufacturing process like PSC Sleeper production, where maximum number of processes and activities are dependent on each other. However, it may also be implemented with ease in each individual set up and activities in any process. In this paper, root-cause analysis has been done using "why, why" analysis to eliminate the defects in sleeper production. This has also helped the project to reduce the rejection rate from $3.1 \%$ to $0.053 \%$ by the end of August'2019. Quick elimination of defects has improved the process of sleeper production. 


\section{References}

1. A.M., Doggett. “A Statistical Comparison of Three Root Cause Analysis Tools.” Journal of Industrial Technology, vol. 20, no. November, 2004, p. 20, doi:10.1074/JBC.274.42.30033.(51).

2. Bonnett, Clifford F. Practicle Railway Engineering. Imperial College Press.

3. Connor, Piers. Track Basics. no. 2, 2017, pp. 1-13, http://www.railway-technical.com/archive/trackbasicsv2.pdf.

4. Mundrey, J. S., and Consultant. Railway Track Engineering. 2007.

5. Rca, The, et al. "Guidance for Performing Root Cause Analysis ( RCA ) with Performance Improvement Projects ( PIPs ).” Qapi, 2012, p. 12.

6. Tikka, Tommi. Reporting Sytem for RCA. no. February, 2011.

7. Vorley, Geoff. "Mini Guide to RCA.” Quality Management \& Training Limited 2008, 2008.

8. Wingler, Dr. F. A. Fundamentals of Rail Way -Track Engineering and Technology ; Quotations for Achieving Sound and Healthy Railway-Tracks of High Quality Fit for Modern "World-Class " Rail Way- Servic E. 2018, pp. 1-20. 